\title{
DESIGN AND USE OF AN EVALUATION TOOL FOR ASSESSMENT OF INSTRUMENTAL SKILLS WITHIN A SUBJECT RELATED TO MATERIALS SCIENCE
}

\author{
V.T. Andrés, A. Sonseca, O. Sahuquillo, R. Benavente \\ Departamento de Ingeniería Mecánica y de Materiales. Universitat Politècnica de València \\ (UPV) (SPAIN)
}

\begin{abstract}
The interest in a competence-based approach in the university, continues increasing at a considerable rate in the European Higher Education Area. Generic competences (specific of the sort of education) assessment is nowadays considered crucial to support socio-educational demands. Nevertheless, the methodologies for the assessment/evaluation of the generic competences and their inclusion in the curriculum has yet to be adequately achieved. Competency-based learning requires either the development of new evaluation tools or adjustment of the existing ones in order to support marking changes needed for new learning-oriented active methodologies. In this sense, questionnaires are an innovative educational tool for competence evaluation although the development of a solid body of knowledge is still a pending task.
\end{abstract}

For this reason, this study proposes a methodological tool based on a questionnaire for rating the assessment (or not) of Specific Instrumental generic competence (instrumental skills), as defined in our university, by undergraduate students. In this regard, a practical intervention was designed to integrate the evaluation of activities related to Instrumental Skills in undergraduate students of Chemical Engineering, taking advantage of a computer practice session programmed as a part of the Materials Science subject. The appropriateness of the developed questionnaire, based on some learning outcomes, as a tool to properly score the competence of interest has been analysed by comparison of the obtained marks with the ones coming from more regular evaluation tools. The results may lead to some interesting conclusions to university professors when creating appropriate competency-based scoring questionnaires.

Keywords: Materials Science, questionnaire, competence assessment, instrumental skills.

\section{INTRODUCTION}

The practice of a competence-based approach in the university system within the frame of the European Higher Education Area is extensively growing [1,2]. Results obtained from research done in this field, recognize as critical the importance of having certain attributes related to abilities and skills, to attain a quality education and facilitate a professional development of the students [3]. Therefore, to contribute to the progress of the high education system, academic institutions have been working hard over the last few years to achieve an international accreditation of their new developed curricular programs, adapted to the demands of the European working models.

Apart from the evaluation of the subjects within the new degrees and programs, it is well known that one driving force behind accreditation is related to the generic and specific competences expected to be achieved by the students along the study plans. These competences can be generic, abilities and skills necessary regardless the education degree, or more specific of the sort of education. Although both are crucial, the generic competences are becoming increasingly more important for the social prosperity, as they will ensure a learning of nature valid in any situation.

Academic institutions are aware of the importance of their competence-based programs, and therefore, have been working hard on this issue. In this sense, authors' University, the Polytechnic University of Valencia (UPV), has defined 13 main competences in the development of its bachelors' and masters' degrees [4]. These competences have arisen as crucial for employers that can base important decisions not only on the subjects that their candidates have studied but also on what they are able to do [5]. Apart from employers, universities themselves can take advantage of competence evaluation as a comparable criterion to promote students' mobility, among others [6,7].

Nevertheless, the assessment of the generic competences and their inclusion in the curriculum has yet to be adequately achieved [8]. It is widely accepted that the competence-based learning requires a 
change in the current pedagogical practices towards a learning-oriented active methodologies able to support a true students curriculum change.

However, this implementation requires new evaluation tools other than exams, to assess the generic competencies indicators. So that, UPV has made a call for innovative projects in this regard (PIME program). Within the frame of one of these projects, authors have proposed a methodological 'outcomes' approach for the assessment of the ability to use the techniques, skills and tools for engineering practice issues. This work presents the developed strategy and evaluation tool based on a questionnaire for the assessment of the competence "Specific Instrumental" within the Materials Science subject in the Chemical Engineering Degree. "Specific Instrumental" is the name of the evaluated competence at UPV and, best fits with "Technology Skills" or "Technical Skills" competences listed at Tuning $[9,10]$ or ABET [11] projects. This competence refers to the use of tools and technologies needed for the professional practice associated with engineering. At the end, its assessment is related with the ability of the student to identify, integrate, and combine the most appropriate tools adequate for facing and solving specific problems or perform projects and experiments.

With this background, a learning experience together with a methodological tool based on a questionnaire, to obtain evidence regarding the acquisition of Specific Instrumental competence skills into Materials Science related subject are proposed in this work. The developed questionnaire addresses the resolution of general and specific problems intended for the evaluation of the degree of ability and comprehension achieved by the students about the specialized software used in a laboratory practice session. In order to check the adequacy or not of the developed questionnaire for the intended task (evaluation of the Specific Instrumental competence), results have been analyzed in the finding of existing correlations between the marks resulting from competence evaluation using the developed tool, and those achieved in the subject (labwork part) evaluated by means of exams and tests.

\section{METHODOLOGY}

The proposed evaluation tool has been tested in a computer practice of Materials Science subject, corresponding to the third year of the Chemical Engineering Degree. The computer practice is focused on the selection of materials for specific applications using the GRANTA Edupack software. Along the practical session, the students work individually with the objective to solve different applied cases from which they had to reach a conclusion about the most suitable material to the intended application with the aid of the software.

In order to facilitate the evaluation process of generic competences, UPV has defined three different competence development levels: Level 1, covering first and second year bachelors' degree; Level 2, covering third and fourth year bachelors' degree; Level 3, covering last year of studies in masters' degree. Learning outcomes increase in complexity with the level [4]. Therefore, the selected subject belongs to the Level 2 whose main learning outcome is expressed as follows:

Integrate correctly the advanced tools of the professional field.

As presented in Table 1, this level establishes the following three different assessment indicators for the Specific Instrumental competence:

- 1. Identification of basic tools and their utility.

- 2. Handling the basic tools autonomously.

- 3. Selection and combination of the appropriate basic tools to carry out a project and/or solve a more complex problem.

Each one of these learning outcomes are divided into four levels of achievement: "D. Not reached", "C. Developing", "B. Good/Adequate" and "A. Excellent/exemplary". The respective numerical intervals assigned to each level are: 0-2.5, 2.6-5.0, 5.1-7.5, 7.6-10. Therefore, depending on the skills reflected in the total score obtained from the questionnaire, the student will reach a level of attainment in the assessed competence (Specific Instrumental). 
Table 1. Rubric to assess the learning outcomes.

\begin{tabular}{l|l|l|l|l}
\hline \hline \multicolumn{1}{c|}{$\begin{array}{c}\text { LEARNING } \\
\text { OUTCOMES }\end{array}$} & \multicolumn{1}{c|}{ D. Not reached } & C. Developing & B. Good/ adequate & $\begin{array}{c}\text { A. Excellent } \\
\text { exemplary }\end{array}$ \\
\hline $\begin{array}{l}\text { Identification of basic } \\
\text { tools and their utility }\end{array}$ & $\begin{array}{l}\text { The student does not } \\
\text { identify the basic } \\
\text { tools }\end{array}$ & $\begin{array}{l}\text { The student identifies } \\
\text { basic tools but does } \\
\text { not recognize his } \\
\text { utility }\end{array}$ & $\begin{array}{l}\text { The student identifies } \\
\text { basic tools and their } \\
\text { main function }\end{array}$ & $\begin{array}{l}\text { The student identifies } \\
\text { additional functions of } \\
\text { basic tools }\end{array}$ \\
\hline $\begin{array}{l}\text { Handling the basic } \\
\text { tools autonomously. }\end{array}$ & $\begin{array}{l}\text { The student is not } \\
\text { able to handle the } \\
\text { tools without detailed } \\
\text { instructions }\end{array}$ & $\begin{array}{l}\text { The student handles } \\
\text { the tools following } \\
\text { detailed instructions }\end{array}$ & $\begin{array}{l}\text { The student handles } \\
\text { tools autonomously }\end{array}$ & $\begin{array}{l}\text { The student handles } \\
\text { tools with ease, } \\
\text { exploiting all their } \\
\text { functionalities }\end{array}$ \\
\hline $\begin{array}{l}\text { Selection and } \\
\text { combination of the } \\
\text { appropriate basic } \\
\text { tools to carry out a } \\
\text { project and/or solve a } \\
\text { complex problem. }\end{array}$ & $\begin{array}{l}\text { The student does not } \\
\text { identify the right tools } \\
\text { for the development } \\
\text { of the project }\end{array}$ & $\begin{array}{l}\text { The student identifies } \\
\text { the tools to be used } \\
\text { but does not combine } \\
\text { them adequately for } \\
\text { the full development } \\
\text { of the project }\end{array}$ & $\begin{array}{l}\text { The student properly } \\
\text { different tools to } \\
\text { complete the } \\
\text { development of the } \\
\text { project }\end{array}$ & $\begin{array}{l}\text { The student finds } \\
\text { new ways to combine } \\
\text { tools for complete the } \\
\text { project in the most } \\
\text { appropriate way } \\
\text { possible, valuing its } \\
\text { pros and cons }\end{array}$ \\
\hline \hline
\end{tabular}

The questionnaire developed as assessment tool for the Specific Instrumental competence, employed in the computer session practice is shown in Table 2. It was distributed at the end of the lab session and marks were not weighted for the final grade, thus eliminating any pressure on the students. The questions were mainly oriented towards methodologies for the resolution of general or specific problems previously addressed and commented in class. This approach will make possible to evaluate at which level the students have internalized the software employed, its limitations and its adequacy to address different Materials Science related problems.

Table 2. Developed questionnaire as assessment tool for Specific Instrumental Competence in Materials Science Computer labworks.

\section{Identify the basic tools and their usefulness.}

I1.1 In which of the following cases of study do you see most convenient the use of GRANTA Edupack?

a) Pre-selection of the most suitable materials that meet certain strength, processing, design (weight, dimensions, finish and shape) and economic requirements.

b) Pre-selection of the most suitable materials that meet certain strength and processing requirements.

I1.2 For which case is GRANTA Edupack a flexible and suitable tool?

a) Consulting behavior of materials against chemical media.

b) Design of manufacturing processes.

\section{Handle basic tools autonomously.}

I2.1 You are required to design a pool diving board capable of withstanding a force $F$ without exceeding a maximum reversible deformation $D$, with the smallest possible weight. The Ashby diagram you would use to begin the selection and which would contain the index to maximize would be:
a) E (Young's Modulus)
b) $E / \rho$ (Young's modulus /density)
c) $\sigma / \rho$ (Stress/density)
d) $\alpha / E$ (Coefficient of expansion/Young's modulus)

I2.2 You have a list of 40 materials that meet the mechanical constraints. In general, what last criterion would you set to narrow down the number of candidates using the GRANTA Edupack?

a) I would take price into account. I would select only the cheapest one.

b) I would take price into account. I would shortlist the 5 cheapest.

c) I would consider the stock availability of the material from the manufacturers in Europe. I would select the one that is available for shipment first.

d) I would consider the weight. I would select only the one with the lowest density. 
13. Select and combine the appropriate basic tools to carry out a professional project and/or solve a complex problem.

13.1 In which case would you be interested in acquiring a GRANTA Edupack license for your company's department?
a) In case the department is dedicated to manufacturing and structural calculation.
b) In case the department is dedicated to design and fabrication.
c) In case the department was dedicated to manufacturing.

I3.2 To which selection method would you relate the GRANTA Edupack tool?

a) In the use of databases (ASTME, SAE, AISI...).

b) Method using Ashby maps.

c) Conventional method based on the Know-How of the company or department.

I3.3 In which stage of the design process do you think the use of GRANTA Edupack is more appropriate?

a) In the conceptual stage to make a pre-selection as an approximation to the final solution.

b) Once the material has already been selected, for its verification.

The set of questions focused on the skills over the software used at three different levels to assess the knowledge acquired by the students. The subdivision in three different levels, will permit to individually evaluate the following three competence indicators: 1) identification of basic tools and their utility, 2) handling of the basic tools autonomously, 3) ability to selection and combination of the appropriate basic tools to carry out a project and/or solve a complex problem. These three indicators correlate directly with the learning outcomes assessment specified in the rubric from Table 1 for the evaluated competence. Therefore, a level of achievement (A, B, C or D) for each learning outcome and for each student can be extracted from the evaluation tool. Additionally, a global competence mark can be calculated as the three indicators average. Similarly, and for validation and comparison purposes, every numerical mark (labwork and global grades) obtained by conventional evaluation tools (tests and exams), can be correlated with a level of achievement (A, B, C or D) by means of the numerical intervals assigned to each level as previously described.

\section{RESULTS}

Most of the labwork sessions of the Materials Science subject, deal with handling some tools/equipment or technologies as well as with using computer resources, thus, they are directly related with the Specific Instrumental competence. In this sense, one can surmise that some correlation might exist between the students labwork grades and the results obtained for the competence evaluation. Therefore, to preliminary check the developed questionnaires' adequacy, the students' level of achievement assessed was compared with the labwork grades results. As global subject grades also take into account the evaluation of the labwork performance, the results were also compared with the students' level of achievement measured with the questionnaires'.

The level of achievement rated per competence indicator and students' percent obtained from the questionnaire is shown in Figure 1. As can be seen, the level of achievement of indicator 2 is the highest with $82 \%$ of the students rated as A. $51 \%$ of the students achieved an A in the indicator 1 while none of them was able to obtain the highest rate regarding the indicator 3 . Both, $I 1$ and $I 2$ are related with the ability of handling tools independently, while $\mathrm{I} 3$ is related with a much more complicated task, as students are required to combine different technical skills to solve general engineering problems. Therefore, majority of the students are rated as $B(39 \%)$ and $C(43 \%)$ instead of $A$ in indicator I3. 


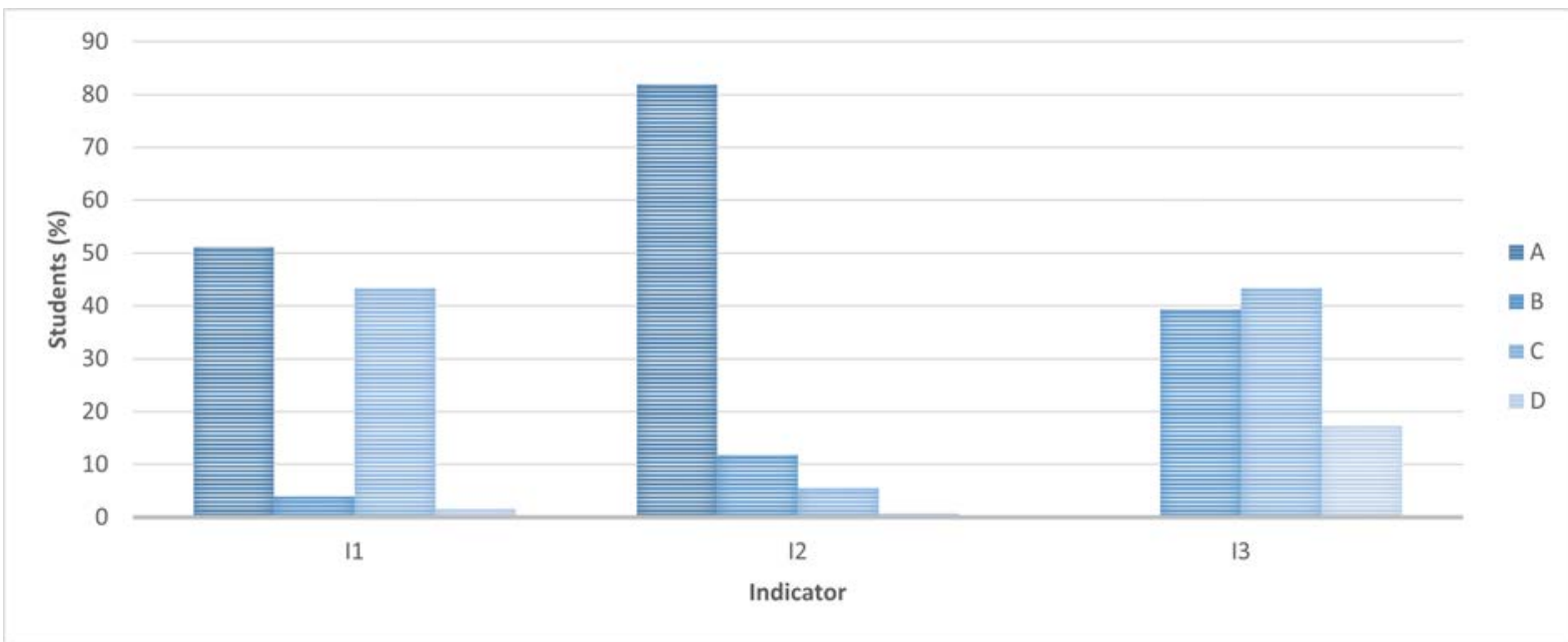

Figure 1. Students percent level of achievement per competence indicator obtained from the questionnaire.

The rate mark per indicator is weighted in order to obtain a general competence value for its evaluation. Figure 2 shows the relation between the Specific Instrumental competence achievement and the labwork sessions rate. The high similarity in the obtained values in each rate for either competence and labwork results, is indicative of an existing relation between competence achievement and labwork performance. Regarding the competence achievement, $41 \%$ of the students rate as $\mathrm{A}, 54 \%$ as $\mathrm{B}, 4 \%$ as $C$ and only $1 \%$ as $D$. The $C$ rate students' percentage slightly increases (from $4 \%$ to $9 \%$ ) while a minor decrease in $A$ and $B$ rates occurs when the competence level of achievement is compared with the labwork results. Therefore, we can consider that to a greater extent, the labwork performance is a direct indication of the skills under evaluation, and corroborates the adequate of the evaluation tool developed for the task.

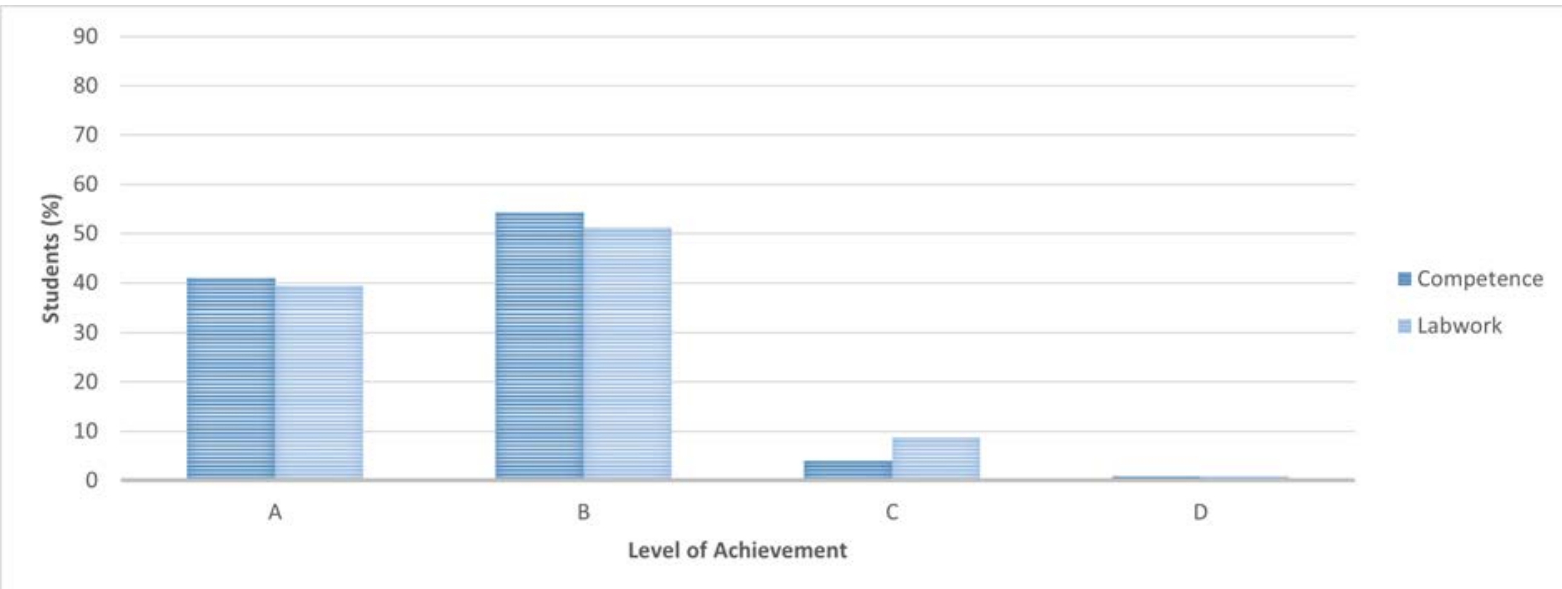

Figure 2. Comparison of the students percentage level of achievement of the competence and labwork rates.

Further, to examinate the application range of the developed evaluation tool, a possible existing correlation between competence, labwork and theory assessment rate was examined. Figure 3 shows the percentage of students per rate regarding the global competence, labwork and subject. Comparing the assessment of the labwork and theory, can be seen that in both cases, most of the students fall in the $B$ rate what is also in agreement with the observations made for the competence evaluation. However, such a clear correlation as between the competence achievement and labwork performance cannot be observed. This sounds logical considering that although there is an evident application of theory basis into the development of the practical sessions, theory exam requires of much more complicated concepts that differ from the ones strengthened in practical lessons. Therefore, as expected, instrumental skills cannot directly be evaluated from the theory mark although some labwork knowledge is required in order to pass that part of the subject. 


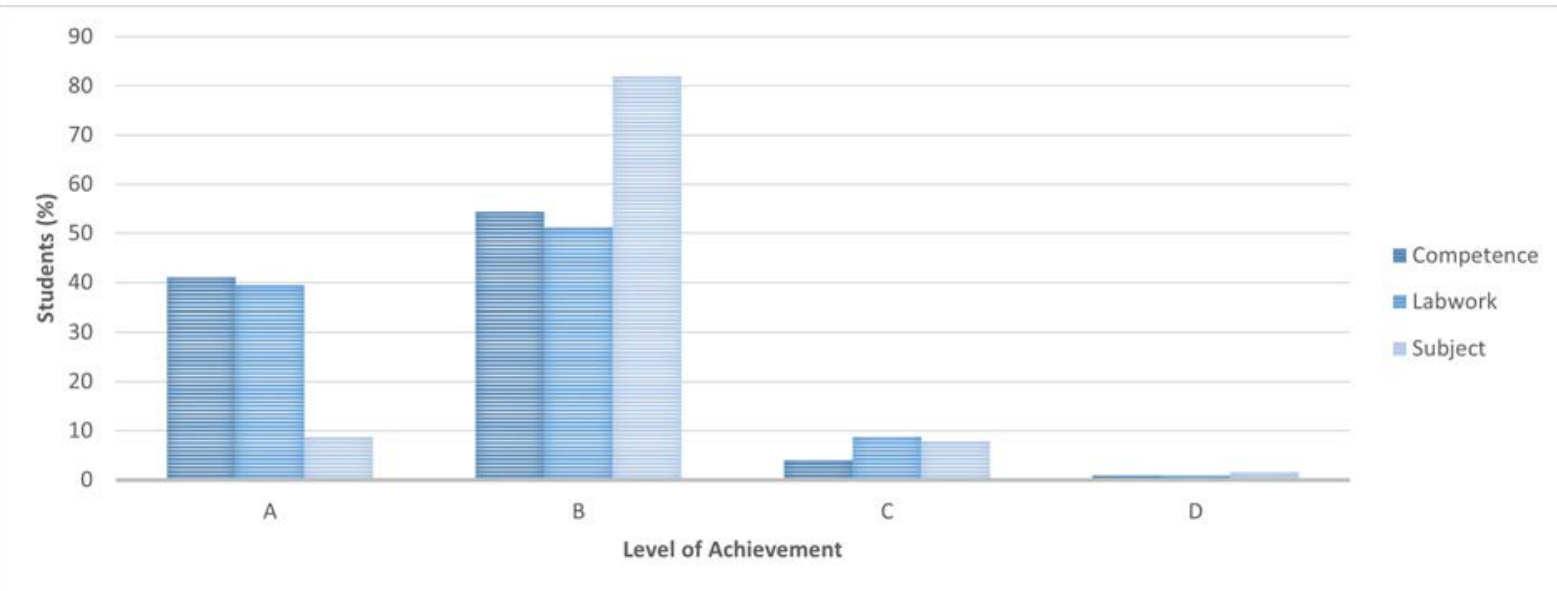

Figure 3. Comparison of the Students percent level of achievement of the competence with lab-work and subject mark rates.

\section{CONCLUSIONS}

A new proposal of a questionnaire adequate to rating the level of acquisition of the Specific Instrumental generic competence, has been designed to be applied within Material Science subject for Chemical Engineering degree, with the idea of stablishing a correlation between the qualitative scoring for the competence and the grades in the labwork.

The comparison between the level of achievement obtained with the designed questionnaire and the marks in laboratory showed a good correlation for these preliminaries results. Therefore, the different rates defined for each level of assessment could be considered as appropriate to grade it. According to this, the data analysis reports that the students obtained the highest level of achievement $(A)$ for the ability of handling tools independently (indicator 2 ), while none of them reached such a level for indicator 3 . This latest indicator is related with the resolution of more complicated task or problems, being therefore, the results coherent with the level of knowledge of undergraduated students. Consequently the proposed tool is shown suitable to grade this generic competence.

Finally, the tool designed has allowed us to obtain encouraging results to continue working along these lines, extending the study to other grades and courses in order to carry out a more complete study.

\section{ACKNOWLEDGEMENTS}

Authors gratefully acknowledge the financial support of the Vicerrectorado de Estudios, Calidad y Acreditación and the Vicerrectorado de Recursos Digitales y Documentación of the Universitat Politècnica de València (Project PIME B/19-20/165 and Project PIME C/20-21/201) and the Instituto de Ciencias de la Educación of the Universitat Politècnica de València (EICE INTEGRAL).

\section{REFERENCES}

[1] A. Sursock and H. Smidt, Trends 2010: A decade of change in European higher education. Brussels: European University Association, 2010.

[2] P. Murias, J.C. de Miguel and D. Rodríguez, "A composite indicator for university quality assesment: The case of Spanish higher education system", Social Indicators research, vol. 89, pp. 129-146, 2007.

[3] M. Rieckmann, "Future-oriented higher education: Which key competencies should be fostered through university teaching and learning?", Futures, vol. 44, pp. 127-135, 2012.

[4] UPV, Competencias Transversales, Accessed 01 April, 2021. Retrieved from http://www.upv.es/contenidos/COMPTRAN.

[5] J. Agten, Bologna as a frame for Competence Based Learning and Supervision?, Katholieke Hogeschool Kempen, 2007. Retrieved from http://www.eassw.org. 
[6] N.J. Entwistle and E.R. Peterson, "Conceptions of learning and knowledge in higher education: Relationships with study behaviour and influences of learning environments", International Journal of Educational Research, vol. 41, pp. 407-428, 2004.

[7] J. Andrews and H. Higson, "Graduate employability, 'Soft skills' versus 'Hard' business knowledge: A european study". Higher Education in Europe, vol. 33, pp. 411-422, 2008.

[8] O. Zlatkin-Troitschanskaia, R.J. Shavelson and C. Kuhn, "The international state of research on measurement of competency in higher education", Studies in Higher Education, vol. 40, no. 3, pp. 393-411, 2015.

[9] Tuning brochure, Tuning Project: Reflexiones y perspectivas de la Educación Superior en América Latina. Informe Final-Proyecto Tuning-América Latina, Accessed 01 April 2021. Retrieved from http://tuning.unideusto.org/tuningal.

[10] Tuning brochure, Tuning Project: General Brochure, Accessed 01 April 2021. Retrieved from http://www.unideusto.org/tuningeu/documents.html.

[11] ABET, Criteria for Accrediting Engineering Programs, Accessed 01 April, 2021. Retrieved from http://www.abet.org. 